\title{
Differential effect of mild and severe pulmonary embolism on the rat lung transcriptome
}

\author{
John Zagorski ${ }^{1}$ and Jeffrey A. Kline $2^{2^{*}}$
}

\begin{abstract}
Background: Pulmonary thromboembolism (PTE) is a common diagnosis and a leading cause of cardiovascular morbidity and mortality. A growing literature has associated PE with systemic inflammation, and global hyper-coagulability, which contribute to lung remodeling and clot recurrence. The source and mechanism of inflammation remains unstudied. In humans, inhibition of cholesterol synthesis with statins decreases biomarkers of inflammation. We test the differential effect of pulmonary vascular occlusion during mild and severe pulmonary embolism on the lung transcriptome.
\end{abstract}

Methods: Experimental PE was induced in adult male rats by injection of 25 micron polystyrene microspheres into the jugular vein. The effect of Mild PE, (2-h right ventricular systolic pressure [RVSP] normal, 18-h RVSP $44 \mathrm{mmHg}$ ) and Severe PE (2-h RVSP > $50 \mathrm{mmHg}$; 18-h RVSP $44 \mathrm{mmHg}$ ) on lungs was assessed by measuring transcriptome-wide changes in gene expression by DNA microarrays.

Results: Severe PE was associated with a large change in lung gene expression and in the expression of KEGG pathways and other gene functional annotation groups. Mild PE was also associated with a large number of significant changes in gene expression and in the expression of KEGG pathways and gene functional annotation groups, even after only $2 \mathrm{~h}$ of PE. Up-regulated pathways included increased adipocytokine, chemokine and cytokine signaling as well as cholesterol synthesis.

Conclusions: Mild PE without acute pulmonary hypertension (PH) increased lung gene expression of inflammatory pathways, including increased cholesterol synthesis. These data indicate that even mild persistent pulmonary vascular occlusion is capable of inciting an inflammatory response from the lung. These data imply the detrimental effect of unresolved pulmonary obstruction from PE.

Keywords: Lung, Pulmonary hypertension, Inflammation, Microarray, GeneSifter, DAVID, Fibrinolysis, Thrombolysis

\section{Background}

Pulmonary embolism (PE) is a common and potentially lethal disease occurring in about 600,000 patients each year in the U.S., leading to as many as 60,000 deaths $[1-5]$.

The most common form of PE is pulmonary thromboembolism (PTE), which results when blood clots, often formed in the deep vasculature of the legs, detach and enter the venous circulation. Circulating clots pass through the

\footnotetext{
* Correspondence: jefkline@iu.edu

2Department of Emergency Medicine and Department of Cellular and Integrative Physiology, Indiana University Medical School, 720 Eskanazi Avenue, Indianapolis, IN 46202, USA

Full list of author information is available at the end of the article
}

right heart and enter the lungs via the pulmonary artery, eventually lodging within the pulmonary vascular tree causing varying degree of pulmonary vascular occlusion and increased pulmonary vascular resistance. PE results in both acute and chronic sequelae. Acute PE causes a sudden increase in RVSP and acute $\mathrm{PH}$, leading to right ventricular (RV) damage and dysfunction. A small subset of patients with unresolved PE go on to develop pulmonary vascular remodeling and RV hypertrophy which develops over time to produce chronic thromboembolic pulmonary hypertension $(\mathrm{CTEPH})$ [6]. A hallmark of CTEPH includes persistent pulmonary vascular occlusion, and a widespread 
inflammatory response [7-11]. Increased lung inflammation has been implicated as a mechanism of reduced angiogenesis, and for increased hyper-coagulability, leading to recurrent PE $[10,12,13]$. Recurrent $\mathrm{PE}$ is a major risk factor for CTEPH development $[8,14]$. Potential causes of inflammation include cells and molecules liberated by clots themselves [15], direct interaction of fibrin and the vessel wall [16], and the effect of shear on the vessel wall and platelets resulting in microparticle formation [9, 17]. Pulmonary vascular occlusion, with deprivation of blood flow to the lung also triggers a brisk inflammatory response [18].

We have previously described a rat model of PE induced by injection of 25 micron polystyrene microspheres into the right jugular vein [18-25]. Although microsphere PE lacks many of the characteristics of PTE such as platelet activation and thrombosis, it does faithfully produce the desired features of pulmonary ischemia and, at high doses, pulmonary hypertension. Rat lungs receiving doses of microspheres that produced acute $\mathrm{PH}$ (Severe PE, right ventricular systolic pressure [RVSP] $\approx 50 \mathrm{mmHg}$ and $10 \%$ animal mortality) had a $>5$-fold increase in recoverable bronchoalveolar lavage (BAL) neutrophils compared to control rats, indicating a neutrophilic inflammation [18]. Strong neutrophil chemotactic activity was measured in isolated alveolar lavage fluid and this activity was inhibited greater $>50 \%$ by treatment with anti-rat CXCL1 antibody. Rat lungs embolized with a lower dose of microspheres (Mild PE, normal RVSP 2-h post-PE and zero mortality), did not show neutrophil or protein accumulation in alveoli, but did show elevated expression of the chemokine genes CXCL1, CXCL2, CXCL3 and CCL2 [18]. These latter data led to a realization that Mild PE was sufficient to induce a pro-inflammatory environment within lung tissues, at least at the level of gene expression, and that lungs might be more sensitive to Mild PE than hearts. In this present study, the transcriptome-wide effect of Mild PE and Severe PE on rat lungs has been examined using DNA microarrays. The primary question was to answer the question whether whether Mild PE, which has been observed to be benign to RV dysfunction and inflammation [20-23], had a disproportionately worse effect on lungs.

\section{Methods}

\section{Animal care}

Experiments were done on male Sprague-Dawley rats weighing between 375 and $400 \mathrm{~g}$. All experiments were conducted in accordance with the NIH Guide For the Care and Use of Laboratory Animals and were approved by the Institutional Animal Care and Use Committee (IACUC) of Carolinas Medical Center, Charlotte NC (4-02-01A and 11-
00-01A). Prior to use, rats had ad libitum access to food and water.

\section{Pulmonary embolism model}

PE was induced in rats by intra-jugular vein injection of 25-micron polystyrene microsphere beads (Duke Scientific \#7525A, Palo Alto CA) as previously published [18-25]. Anesthetized rats were injected with either 1.3 or 2.0 million microspheres/100 g body weight to produce Mild $\mathrm{PE}$ and Severe PE, respectively. Control rats were injected with $0.15 \mathrm{ml} / 100 \mathrm{~g}$ of $0.01 \%$ Tween 20 (the resuspension vehicle for microspheres), which was equivalent in volume to the Severe PE dose of microspheres. These treatment groups are referred to as "Vehicle" or "Veh".

\section{Microarray analyses}

Lung tissue samples from whole right lung lobes used for this study are the same as those collected for a previously published study [18]. In that study, Mild PE produced 2-h RVSP that was not statistically significant from RVSP in control rats (mean $39 \mathrm{mmHg}$ for Mild $\mathrm{PE}$ verses mean $32 \mathrm{mmHg}$ for controls, $p>0.05$ ) while 2-h Severe PE caused elevation of RVSP to $>50 \mathrm{mmHg}$ [18]. Lungs were also collected from rats after 18-h of PE but RVSP was not measured. In subsequent studies, Mild PE was shown to cause a rise in 18-h RVSP to mean $44+/-1.3 \mathrm{mmHg}(p<0.05$ relative to vehicle) while the RVSP in 18-h Severe PE was shown to fall from a peak of $>50 \mathrm{mmHg}$ to $44+/-0.9 \mathrm{mmHg}[20,22]$. We have consistently concluded that Severe PE is associated with $\mathrm{PH}$ for the full time course of $2-18 \mathrm{~h}$ while Mild PE consistently shows PH only at the 18-h time. RNA was prepared from crushed whole right lung tissue which had been stored at $-80{ }^{\circ} \mathrm{C}$ using the acidphenol guanidinium isothiocyanate method of Chomczynski and Sacchi [26] followed by a second round of purification on RNeasy columns (Qiagen, Germantown, $\mathrm{MD})$. Total lung RNA was prepared for microarray hybridization by standard Affymetrix procedures as previously described and checked for RNA integrity on agarose gels prior to use [23, 24]. Fragmented cRNAs were then hybridized to Affymetrix Rat Genome 230 v2.0 microarrays, washed and fluorescently stained in the Affymetrix Fluidics Station 400 using Affymetrix procedures. Each array was scanned twice by an Agilent Gene Array Scanner G2500A (Agilent Technologies, Palo Alto, CA).

Microarray data were initially analyzed with GeneSifter web-based software (Geospiza, Seattle, WA; (http://www.genesifter.net). Affymetrix ".cel” files were up-loaded to the GeneSifter web site using GC-RMA normalization into "Pair-wise" and "Project" folders for access to $t$-test and ANOVA statistical methods, respectively. A 2-way ANOVA was used to initially 
compare the six treatment groups using time as the first factor (2-h and 18-h) and microsphere dose as the second factor (Vehicle, Mild PE, Severe PE). A 1.5-fold expression difference threshold and Benjamini and Hochberg correction for false discovery $(p<0.05)$ was used as "pass" criteria. Genes that passed any one of the criteria of time, dose or interaction were accepted. The 6 sample groups used in the 2-way ANOVA were then subjected to hierarchical clustering to determine the similarities of the groups using the GeneSifter "Cluster" function.

Separate 1-way ANOVAs were used to compare the three 2-h treatment groups and three 18-h treatment groups for genes with related expression patterns based on the factor of microsphere dose (1.5-fold expression difference threshold relative to 2 -h vehicle and 18 -h vehicle groups as controls, respectively, Benjamini and Hochberg correction for false discovery, $p<0.05)$. Clustering of genes within the 2-h and 18-h ANOVAs were done using the GeneSifter PAM function (Partitioning Around Medoids) with a user-defined 12-cluster output. PAM searches a gene list for groups of genes (clusters) within the list that have a characteristic that is shared by all genes within that group but different from genes within other groups (hence, "clustering"). The characteristic used by GeneSifter was the pattern of expression each gene showed for the Vehicle, Mild PE and Severe PE treatments. GeneSifter allowed the user to specify the number of clusters that the entire gene list would be sorted into. For the analyses in Figs. 2 and 3, the 2-h and 18 -h gene lists were sorted into 12 clusters. This number of clusters was determined empirically as the fewest number of clusters which yielded Mild PEselective and Severe PE-selective expression patterns for the 2-h ANOVA data. These patterns were defined as expression patterns in which the change in expression from control was maximal between Vehcile and Mild PE and between Mild PE and Severe PE, respectively.

Pairwise comparison of treatment groups was done with GeneSifter using 2-sided unpaired t-tests with a 1.5 -fold expression difference threshold relative to vehicle groups and with Benjamini and Hochberg correction for false discovery, $p<0.05$.

Excel spreadsheet exports of 2-h and 18-h GeneSifter ttests were used to prepare gene lists for further analysis using DAVID (Database for Annotation, Visualization and Integrated Discovery; http://david.abcc.ncifcrf.gov; [27, 28]). Lists of official gene symbols were first separated into new lists of up-regulated and down-regulated probesets from the pairwise $t$-test spreadsheets in Additional file 2A-C (2-h data) and 2D-F (18-h data). The six possible combinations of treatment times and PE doses were examined: 2-h and 18-h Mild PE verses Vehicle, Severe PE verses Vehicle, and Mild PE verses Severe PE expression. "UP" and "DOWN" lists of official gene symbols were then separately pasted into the search input in DAVID. DAVID analyzes gene lists and identifies all of the annotations that are attributed to each gene in the list. Gene annotations are categories of gene function, protein structural features, biochemical pathways and other shared gene or protein properties that are manually given by database curators to all genes and proteins. DAVID then produces several types of output that group the members of the input gene list into these annotations and determines statistical significance by comparing the number of genes from the submitted gene list that are present in each annotation with the total number of genes that are in the annotation (this is an "enrichment calculation"). Functional annotation charts were generated using DAVID default stringency settings ("moderate"). Each downloaded chart was a spreadsheet containing a list of all known annotations that contained at least one gene from the input list of PE genes from the $t$-test and the probability that the input list of PE genes was enriched in genes of that annotation. Final annotation charts were then assembled by merging the UP- and DOWN-enriched annotations for each combination of PE dose and time. These charts were then reduced in complexity by discarding annotation terms that were not significantly enriched in the input PE gene list ( $t$-test, Benjamini and Hochberg values $>0.05$ ) and by discarding all Gene Ontology (GO) terms in the DAVID output regardless of statistical significance. GO term annotations greatly increased the length of the annotation lists but have limited investigative value in the opinion of the authors. All microarray data have been deposited in the NIH/NCBI "GEO" database (http://www.ncbi.nlm.nih.gov/ projects/geo; GEO accession number GSE13535).

\section{Results}

\section{Six-group ANOVA, gene clustering, and pair-wise t-tests} of treatment groups

A comprehensive summary of all microarray data was first generated by comparing the six treatment groups (Mild PE, Severe PE and Vehicle each at 2-h and 18-h) in this study using a 2-way ANOVA, using the GeneSifter software suite (1.5-fold expression change minimum, Benjamini and Hochberg correction for false discovery, $p<0.05$ ). The data is contained in Additional file 1 and shows that 8075 Affymetrix probesets passed the ANOVA for at least one of the tests (Factor 1, time; Factor 2, dose; interaction). The data from the ANOVA was then subjected to hierarchical clustering using GeneSifter to define the relationships between the six treatment groups. This output is summarized in the dendrogram shown in Fig. 1. The three 2-h groups were closely associated, as were the 18-h Mild PE and 18-h Severe PE groups while the 18-h vehicle clustered with the 2-h vehicle.

The six groups were also compared pair-wise (t-test, 1.5-fold expression change minimum, Benjamini and 


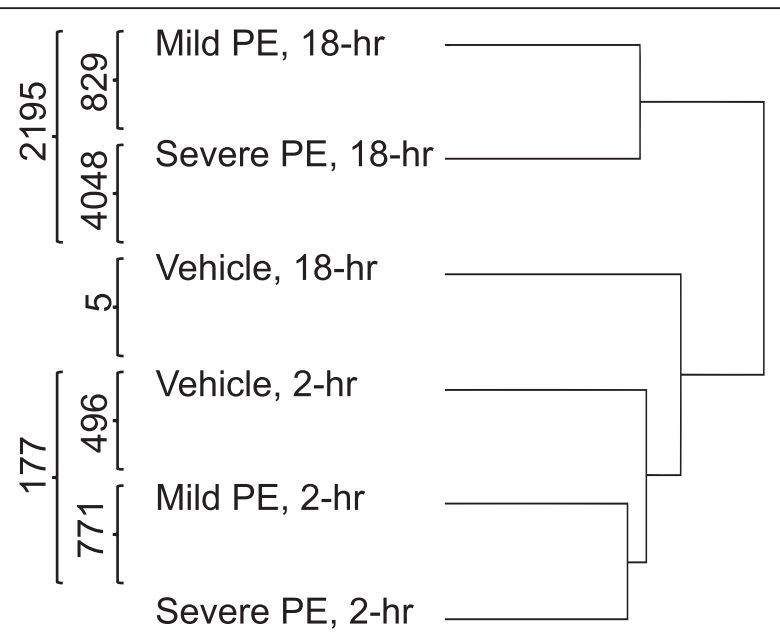

Fig. 1 Hierarchical clustering of six treatment groups and results of pair-wise t-tests. Expression data from the six treatment groups were first compared by 2-way ANOVA using PE time as factor-1 and microsphere dose as factor-2. Relationships among the six treatments were determined using GeneSifters hierarchical clustering function applied to the 8075 Affymetrix probesets that passed the 2way ANOVA. The separation of the six treatment groups on the dendrogram is based on relative Euclidean distance. Numerical data superimposed on the dendrogram are the results of pair-wise t-tests between the treatment groups

Hochberg correction, $p<0.05)$. These results are summarized on the left side of Fig. 1, and are available as spreadsheets in Additional file 2A-C and D-F (2-h groups and 18-h groups, respectively). For the Mild PE treatment groups there was a 4.43-fold increase in the number of significantly altered probesets between 2 and $18 \mathrm{~h}$ after PE (496 verses 2195). Similarly, for the Severe PE treatment groups there was 22.9-fold increase in the number of significantly altered probesets between 2 and $18 \mathrm{~h}$ after PE (177 verses 4048). Comparison of the Mild PE and Severe PE treatment groups at the same times revealed that the $18 \mathrm{~h}$ Severe PE group had 1.84-fold more altered probesets than the 18 h Mild PE group (4048 verses 2195), while the Severe PE group had fewer altered probesets at $2 \mathrm{~h}$ than the Mild PE group (177 verses 496). In a separate comparison of the two vehicle control groups $(2 \mathrm{~h}$ and $18 \mathrm{~h}$ ), only five probesets were significantly different, three of which were annotated in the GeneSifter database as "transcribed loci" only (data not shown). Taken together, these data indicated that although Severe PE produced a larger change in gene expression than Mild PE, Mild PE was sufficient to produce a robust change in lung gene expression.

\section{Separate analyses of 2-h and 18-h treatment groups}

The responses of rats to mild PE and Severe PE were compared using separate 1-way ANOVAs of the 2-h and 18-h treatments with GeneSifter (expression difference threshold $>1.5$-fold, $t$-test $<0.05$, Benjamini and Hochberg). For the three 2-h treatment groups 775 probesets were altered in expression relative to the 2 -h vehicle control, while 4360 probesets were altered in the 18 - $h$ groups relative to the 18-h vehicle control (1.5-fold expression difference threshold, $t$-test $<0.05$, Benjamini and Hochberg). The altered probesets in the 2-h and 18-h ANOVAs were then clustered into similar expression patterns with GeneSifter using the PAM function (Partitioning Around Medoids) with a user-designated output of 12 clusters for each ANOVA. These data are presented in Figs. 2 and 3 for 2-h and 18-h treatment groups, respectively.

The PAM-clustering of the 2-h ANOVA data is shown in Fig. 2, and clearly indicates three distinct patterns. 5 of 12 clusters had a "Mild PE-selective" pattern (clusters 3, 6, 8, 10 and 12). Probesets in these clusters had greater changes in expression between the vehicle and Mild PE samples than between the Mild PE and Severe PE samples. 2 of 12 clusters had a "Severe PE-selective" pattern (clusters 4 and 5). Probesets in these clusters had greater changes in expression between the Mild PE and Severe PE samples than between the vehicle and Mild PE samples. Curiously, 4 of 12 clusters had a Mild PE-specific pattern (clusters 1, 2, 9 and 11). Probesets in these clusters had peak increases or decreases in expression between the Vehicle and Mild PE treatments but minimal change in expression between the Mild PE ad Severe PE treatments. The magnitudes of the Mild PE expression changes in two of these clusters were within a single $\log 2$ increment of the vehicle and Severe PE groups (clusters 1 and 2) while the magnitudes of the Mild PE expression changes in the other two clusters (9 and 11) reached $4 \log 2$ increments of the vehicle and Severe PE groups. These four clusters, and clusters 9 and 11 in particular, suggest that there were opposing signals for up- and down-regulation of gene expression in the Mild PE and Severe PE groups.

The PAM-clustering of the 18-h ANOVA data is shown in Fig. 3. Clustering of the 18-h treatment groups resulted in fewer clusters with obvious Mild PE-selective and Severe PE-selective gene expression than observed for the 2-h ANOVA. A plurality of clusters had "non-selective" patterns of gene expression (2, 3, 7, 8 and 10). Probesets in these clusters had nearly identical changes in expression between the vehicle and Mild PE samples and Mild PE and Severe PE samples. 4 of 12 clusters had a Mild PE-selective pattern (clusters 4, 5, 11 and 12) while two clusters (1 and 9) were intermediate between Mild PE-selective and nonselective. In contrast to the 2 -h treatments, none of the clusters were indicative of Severe PE-selective expression.

\section{Enrichment of PE genes in functional annotations}

Gene expression data from the pairwise t-tests of Mild PE and Severe PE treatment groups (Additional file 2A - F) were examined for significant enrichment of PE-altered probesets present in database annotations using DAVID 


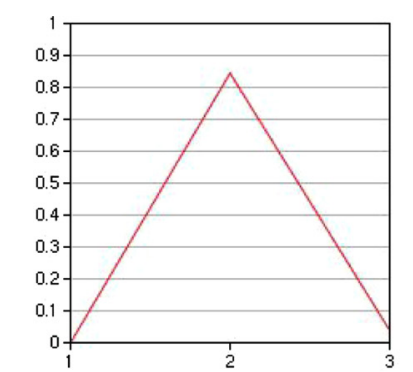

Cluster-1 92 Probesets

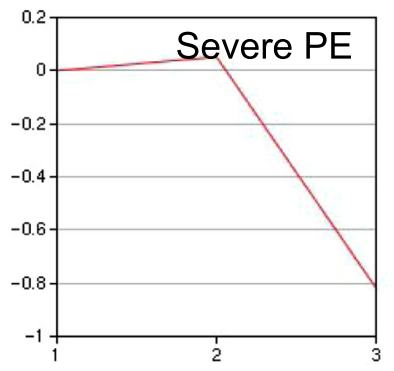

Cluster-5 78 Probesets

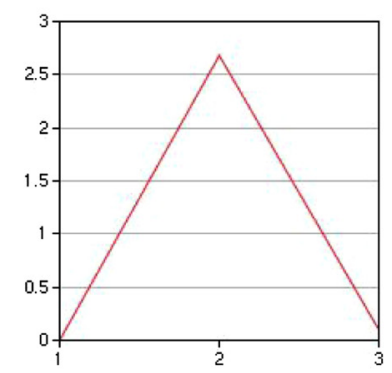

Cluster-9 33 Probesets

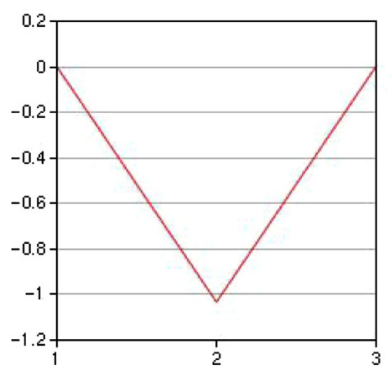

Cluster-2 87 Probesets

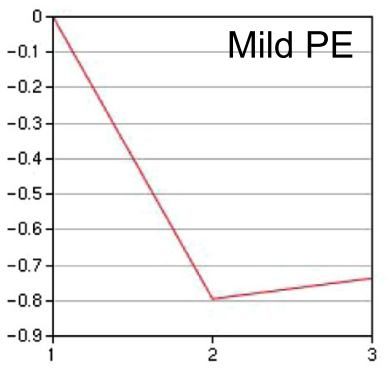

Cluster-6 85 Probesets

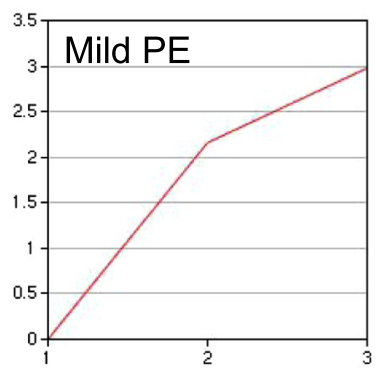

Cluster-10 31 Probesets

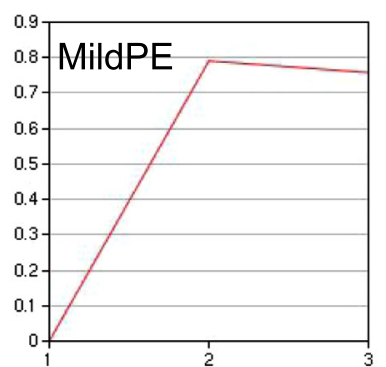

\section{Cluster-3} 93 Probesets

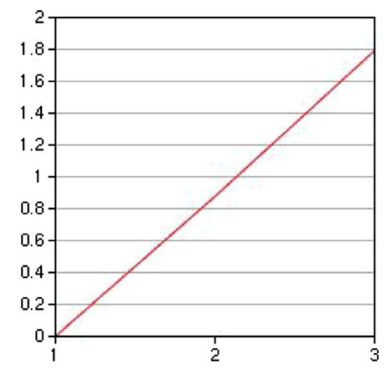

Cluster-7 61 Probesets

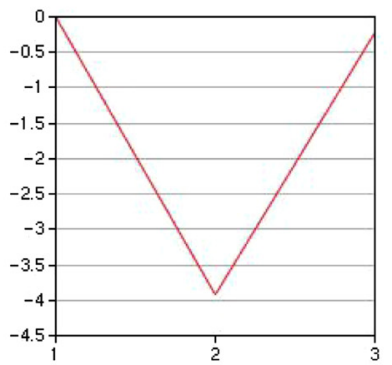

Cluster-11 17 Probesets
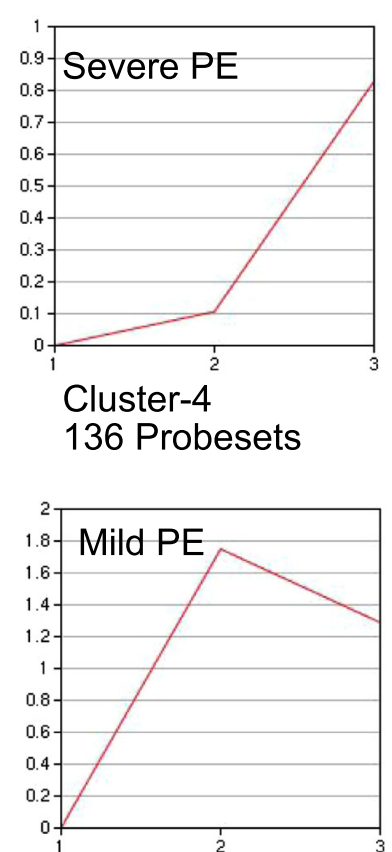

Cluster-8 51 Probesets

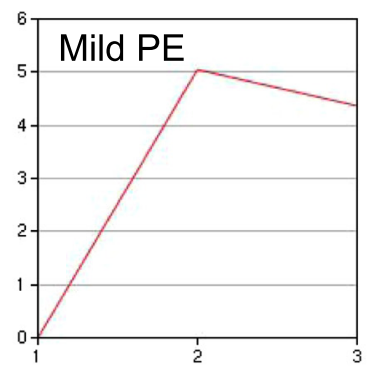

Cluster-12 11 Probesets

Fig. 2 Clustering of 2-h treatment groups. Expression data from the three 2-h treatment groups (Vehicle, Mild PE, Severe PE; $x$-axis labels 1, 2, 3, respectively) were clustered using the PAM function of GeneSifter. A 12-cluster output was manually specified. Expression relative to Vehicle groups is provided on y-axes and is log2 transformed. The labels "Mild-PE" and "Severe-PE" are used to refer to patterns of expression that are primarily altered between the Vehicle and Mild PE groups or Mild PE and Severe PE groups, respectively

web-based software (KEGG pathways, INTERPRO, SMART and SP_PIR database terms; GO terms excluded). Tables 1 and 2 summarize the functional annotations enriched in the Mild PE and Severe PE treatment groups, respectively.

Functional annotations enriched in the Mild PE treatment groups relative to time-matched vehicle controls are shown in Table 1. Annotations unique to Mild PE treatment groups are highlighted with bold font and italics while annotations common to Low- and Severe PE are in standard font. Blank cells in the data indicate that an annotation was not significantly over-represented at a particular time and treatment combination. At the 2-h time, the majority of annotations (10 of 21 total annotations) were unique to Mild PE, while a minority (11 of 21) were shared with the Severe PE 2-h group (Table 2). Conversely, at 18 -h only 5 of 22 total annotations were unique to Mild PE (23\%) while 17 of 22 (77\%) were shared with the Severe PE group (Table 2). These data support a distinct mechanistic difference between Mild and Severe PE. If Mild PE were merely a less robust manifestation of Severe PE, all annotations present during Mild PE would be expected to be present during Severe PE.

Functional annotations enriched in the Severe PE treatment groups relative to time-matched vehicle controls are shown in Table 2. Annotations unique to Severe PE treatment groups are highlighted with bold font and italics while annotations common to Low PE and Severe PE are 


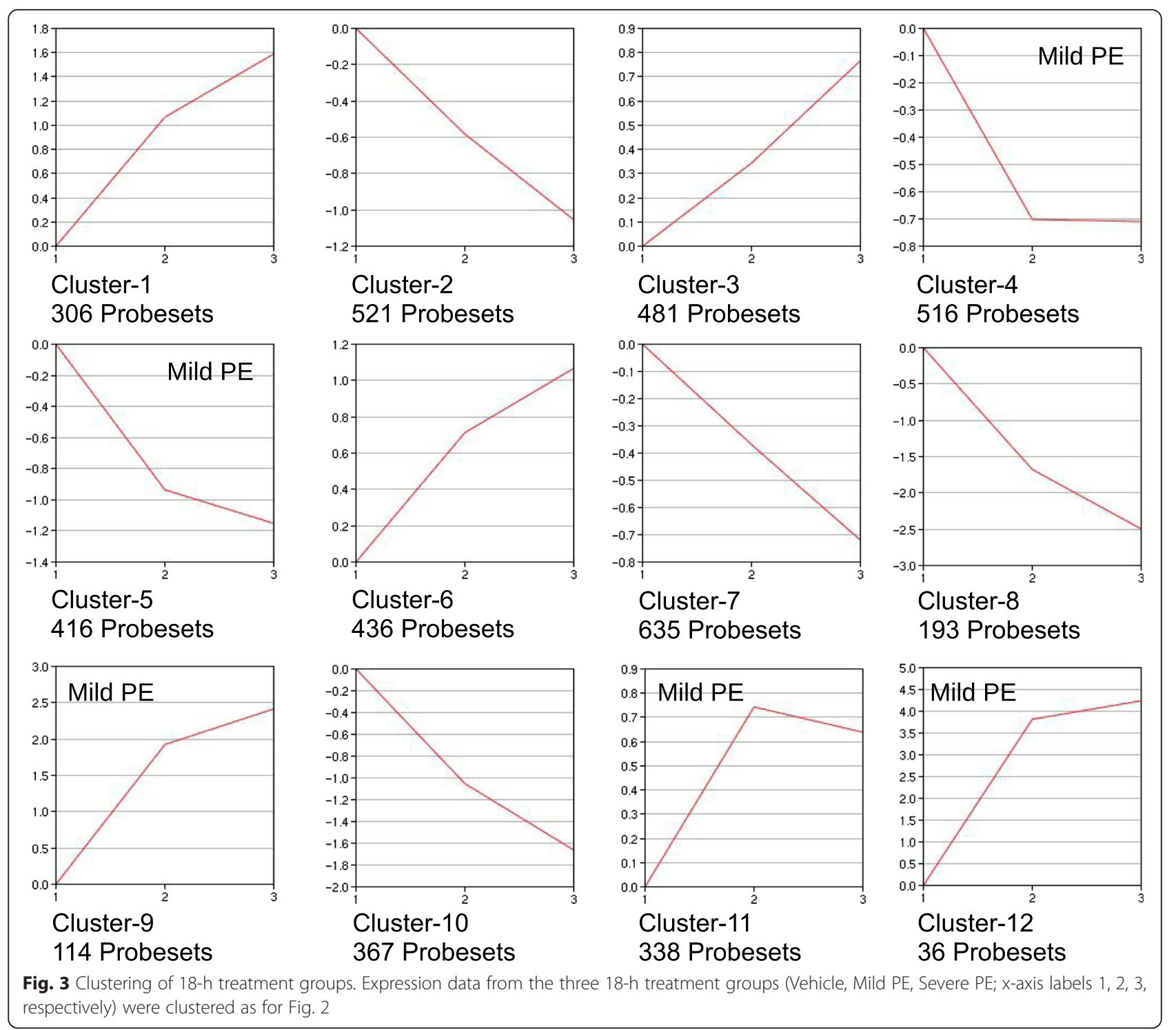

in standard font. It is noteworthy that the data in Table 2 showed a distinct separation of annotations between the two times. Of the 57 total annotations listed in the table only one, "SP-PIR chemotaxis", was present at both times. The remaining 56 annotations were present at only one of the time points. This pattern was not seen with the Low PE data in Table 1 in which a greater proportion of the total annotations were present at both times. Together, these data suggest a rapid "progression" of the Severe PE condition at the transcriptional level compared to a more gradual transcriptional "progression" for Mild PE.

\section{Annotations unique to mild PE}

Further examination of the Mild PE expression data in Table 2 revealed that 13 of 35 total annotations were unique to Mild PE. Several of these unique annotations involved pro-inflammatory KEGG pathways or protein families. The KEGG pathways were: rno04920 "adipocytokine signaling", rno04062 "chemokine signaling", rno04060 "cytokine-cytokine receptor", and rno04620 "Toll-like receptor signaling". Rno04010 "MAPK signaling pathway" was also present, but this pathway intersects with diverse cellular processes beside inflammation. The Interpro annotation IPR000827 "small cytokine C-C" and Protein Information Resource annotation PIRSF001950 "small inducible chemokine" were also present. The presence of gene annotations unique to the 2-h Mild PE treatment, which shares little physiological similarity with Severe PE, continue to support a conclusion that Mild PE and Severe PE may be mechanistically dissimilar at the transcriptional level.

\section{Are mild PE and severe PE related?}

The possible similarities between the 18-h Mild PE and 2-h Severe PE found in Tables 1 and 2 prompted a direct 
Table 1 DAVID Functional Annotation Charts, 2-h and 18-h Mild PE verses Vehicle

\begin{tabular}{|c|c|c|c|c|c|c|c|c|c|c|c|}
\hline \multirow[t]{2}{*}{ Category } & \multirow[t]{2}{*}{ Term } & \multicolumn{5}{|c|}{ a2-h Mild-PE vs. Vehicle } & \multicolumn{5}{|c|}{ 18-h Mild-PE vs. Vehicle } \\
\hline & & $\mathrm{Ct}$ & $\%$ & Dir & Fold & $\mathrm{B} \& \mathrm{H}$ & $\mathrm{Ct}$ & $\%$ & Dir & Fold & $\mathrm{B} \& \mathrm{H}$ \\
\hline SP_PIR & acetylation & & & & & & 78 & 14.03 & UP & 1.51 & 0.009 \\
\hline rno04920 & Adipocytokine signaling pathway & 6 & 2.93 & $U P$ & 7.47 & 0.015 & & & & & \\
\hline rno00970 & Aminoacyl-tRNA biosynthesis & & & & & & 8 & 1.44 & UP & 5.56 & 0.017 \\
\hline rno04210 & Apoptosis & 6 & 2.93 & $U P$ & 5.89 & 0.028 & & & & & \\
\hline rno00330 & Arginine and proline metabolism & & & & & & 9 & 1.62 & UP & 4.72 & 0.015 \\
\hline rno05217 & Basal cell carcinoma & & & & & & 10 & 1.11 & D & 4.28 & 0.016 \\
\hline IPR004827 & Basic-leucine zipper (bZIP) transcription factor & 7 & 3.41 & UP & 11.97 & 0.003 & & & & & \\
\hline SM00338 & BRLZ & 7 & 3.41 & UP & 10.46 & 0.001 & & & & & \\
\hline rno04062 & Chemokine signaling pathway & 12 & 5.85 & UP & 5.85 & 0.000 & 20 & 3.60 & UP & 3.25 & 0.001 \\
\hline SP_PIR & chemotaxis & 9 & 4.39 & UP & 22.67 & 0.000 & 11 & 1.98 & UP & 10.30 & 0.000 \\
\hline rno04610 & Complement and coagulation cascades & & & & & & 10 & 1.80 & UP & 3.97 & 0.019 \\
\hline SP_PIR & cytokine & 11 & 5.37 & UP & 9.02 & 0.000 & 16 & 2.88 & UP & 4.88 & 0.000 \\
\hline rno04060 & Cytokine-cytokine receptor interaction & 10 & 4.88 & $U P$ & 4.24 & 0.008 & 23 & 4.14 & UP & 3.25 & 0.000 \\
\hline rno04623 & Cytosolic DNA-sensing pathway & 5 & 2.44 & $U P$ & 9.07 & 0.024 & & & & & \\
\hline$S P \_P I R$ & disulfide bond & & & & & & 76 & 13.67 & UP & 1.43 & 0.044 \\
\hline SP_PIR & dna-binding & 20 & 9.76 & UP & 2.43 & 0.023 & & & & & \\
\hline rno00982 & Drug metabolism & & & & & & 13 & 1.45 & $\mathrm{D}$ & 3.94 & 0.004 \\
\hline rno04512 & ECM-receptor interaction & & & & & & 14 & 1.56 & $\mathrm{D}$ & 3.77 & 0.005 \\
\hline PIRSF001719 & fos transforming protein & 4 & 1.95 & UP & 59.84 & 0.001 & & & & & \\
\hline IPR000837 & Fos transforming protein & 4 & 1.95 & UP & 40.08 & 0.010 & & & & & \\
\hline rno00480 & Glutathione metabolism & & & & & & 9 & 1.00 & $\mathrm{D}$ & 3.93 & 0.042 \\
\hline rno04640 & Hematopoietic cell lineage & 6 & 2.93 & $U P$ & 6.42 & 0.022 & & & & & \\
\hline rno00340 & Histidine metabolism & & & & & & 7 & 0.78 & $\mathrm{D}$ & 6.37 & 0.017 \\
\hline SP_PIR & inflammatory response & 8 & 3.90 & UP & 16.01 & 0.000 & 11 & 1.98 & UP & 8.18 & 0.000 \\
\hline rno04010 & MAPK signaling pathway & 10 & 4.88 & $U P$ & 3.14 & 0.029 & & & & & \\
\hline rno00980 & Metabolism of xenobiotics by cytochrome P450 & & & & & & 13 & 1.45 & $\mathrm{D}$ & 4.73 & 0.002 \\
\hline rno04621 & NOD-like receptor signaling pathway & 9 & 4.39 & UP & 12.11 & 0.000 & 10 & 1.80 & UP & 4.49 & 0.016 \\
\hline$S P \_P I R$ & oxidoreductase & & & & & & 42 & 4.68 & $D$ & 1.89 & 0.034 \\
\hline rno05020 & Prion diseases & & & & & & 7 & 1.26 & UP & 5.56 & 0.028 \\
\hline SP_PIR & ribosome biogenesis & & & & & & 7 & 1.26 & UP & 8.85 & 0.007 \\
\hline SM00199 & SCY & 8 & 3.90 & UP & 16.89 & 0.000 & 10 & 1.80 & UP & 8.76 & 0.000 \\
\hline IPR000827 & Small chemokine, C-C group, conserved site & 4 & 1.95 & $U P$ & 25.50 & 0.033 & & & & & \\
\hline IPR001811 & Small chemokine, interleukin-8-like & 8 & 3.90 & UP & 19.35 & 0.000 & 10 & 1.80 & UP & 8.70 & 0.001 \\
\hline PIRSF001950 & small inducible chemokine, C/CC types & 5 & 2.44 & $U P$ & 24.93 & 0.001 & & & & & \\
\hline rno04620 & Toll-like receptor signaling pathway & 9 & 4.39 & UP & 8.34 & 0.000 & & & & & \\
\hline
\end{tabular}

Functional annotations significantly over-represented in the lists of up-regulated and down-regulated genes during 2-h and 18-h Low-PE. Annotations unique to Low-PE are highlighted in bold italics; annotations common to Low-PE and High-PE (Table 2) are in standard font. Key: "Ct.", number genes from a GeneSifter pairwise $t$-test result (Additional file 3A-C) that were present in the functional annotation indicated; "\%", percent of genes contained within a list that were present in an annotation; "Dir, UP", annotations that were identified by DAVID when up-regulated genes were used as the search query; "Dir, D", annotations that were identified by DAVID when downregulated genes were used as the search query. "Fold", expression relative to vehicle group; B\&H, value of Benjamini and Hochberg adjustment for false discovery following $t$-test. ${ }^{\mathrm{a}} \mathrm{No} 2$-h DOWN annotations meet $\mathrm{B} \& \mathrm{H}<0.05$

comparison between these two treatment groups. These data are presented in Table 3. However, only 6 of 36 annotations present in either of the two treatments were shared by both: SP-PIR chemotaxis, SP_PIR cytokine,
SP_PIR "inflammatory response", rno04621 "NOD-like receptor signaling pathway", SM00199 "SCY" and IPR001811 "small chemokine interleukin-8-like". The remaining 31 annotations which were enriched in either 
Table 2 DAVID Functional Annotation Charts, 2-h and 18-h Severe PE verses Vehicle

\begin{tabular}{|c|c|c|c|c|c|c|c|c|c|c|c|}
\hline \multirow[t]{2}{*}{ Category } & \multirow[t]{2}{*}{ Term } & \multicolumn{5}{|c|}{ a2-h Severe PE verses Vehicle } & \multicolumn{5}{|c|}{ 18-h Severe PE verses Vehicle } \\
\hline & & $\mathrm{Ct}$ & $\%$ & Dir & Fold & $\mathrm{B} \& \mathrm{H}$ & $\mathrm{Ct}$ & $\%$ & Dir & Fold & $\mathrm{B} \& \mathrm{H}$ \\
\hline SP_PIR & acetylation & & & & & & 183 & 17.72 & UP & 1.86 & 0.000 \\
\hline$S P \_P I R$ & activator & 7 & 7.29 & UP & 5.58 & 0.025 & & & & & \\
\hline$S P \_P I R$ & acute phase & & & & & & 7 & 0.68 & $U P$ & 4.89 & 0.047 \\
\hline rno00520 & $\begin{array}{l}\text { Amino sugar and nucleotide } \\
\text { sugar metabolism }\end{array}$ & & & & & & 12 & 1.16 & $U P$ & 4.37 & 0.002 \\
\hline rno00970 & Aminoacyl-tRNA biosynthesis & & & & & & 12 & 1.16 & UP & 4.70 & 0.002 \\
\hline SP_PIR & Aminoacyl-tRNA synthetase & & & & & & 10 & 0.97 & UP & 5.11 & 0.003 \\
\hline rno00330 & Arginine and proline metabolism & & & & & & 11 & 1.06 & UP & 3.25 & 0.046 \\
\hline rno05412 & $\begin{array}{l}\text { Arrhythmogenic right ventricular } \\
\text { cardiomyopathy (ARVC) }\end{array}$ & & & & & & 15 & 0.96 & $D$ & 2.56 & 0.040 \\
\hline rno05217 & Basal cell carcinoma & & & & & & 12 & 0.77 & $\mathrm{D}$ & 2.97 & 0.036 \\
\hline IPR011700 & Basic leucine zipper & 4 & 4.17 & UP & 41.80 & 0.004 & & & & & \\
\hline IPR004827 & Basic-leucine zipper (bZIP) transcription factor & 8 & 8.33 & UP & 28.54 & 0.000 & & & & & \\
\hline SM00338 & BRLZ & 8 & 8.33 & UP & 20.66 & 0.000 & & & & & \\
\hline IPR011616 & bZIP transcription factor, bZIP-1 & 4 & 4.17 & UP & 25.44 & 0.015 & & & & & \\
\hline$S P \_P I R$ & Chaperone & & & & & & 18 & 1.74 & $U P$ & 2.78 & 0.006 \\
\hline SP_PIR & chemotaxis & 4 & 4.17 & UP & 20.78 & 0.025 & 9 & 0.87 & UP & 4.43 & 0.016 \\
\hline$S P \_P I R$ & Cholesterol biosynthesis & & & & & & 9 & 0.87 & UP & 7.47 & 0.000 \\
\hline rno04610 & Complement and coagulation cascades & & & & & & 17 & 1.65 & UP & 3.80 & 0.000 \\
\hline SP_PIR & cytokine & 9 & 9.38 & UP & 15.21 & 0.000 & & & & & \\
\hline SP_PIR & DNA binding & 6 & 6.25 & UP & 7.38 & 0.028 & & & & & \\
\hline SP_PIR & dna-binding & 15 & 15.63 & UP & 3.75 & 0.002 & & & & & \\
\hline UP_SEQ & DNA-binding region: Basic motif & 10 & 10.42 & UP & 15.44 & 0.000 & & & & & \\
\hline UP_SEQ & domain: Leucine-zipper & 9 & 9.38 & $U P$ & 19.96 & 0.000 & & & & & \\
\hline rno00982 & Drug metabolism & & & & & & 20 & 1.28 & $\mathrm{D}$ & 3.51 & 0.000 \\
\hline rno04512 & ECM-receptor interaction & & & & & & 17 & 1.09 & D & 2.65 & 0.020 \\
\hline SM00180 & EGF_Lam & & & & & & 9 & 0.58 & $D$ & 5.44 & 0.020 \\
\hline IPR002049 & EGF-like, laminin & & & & & & 9 & 0.58 & $D$ & 5.98 & 0.026 \\
\hline$S P \_P I R$ & endoplasmic reticulum & & & & & & 63 & 6.10 & $U P$ & 2.04 & 0.000 \\
\hline PIRSF001719 & fos transforming protein & 4 & 4.17 & UP & 109.2 & 0.000 & & & & & \\
\hline IPR000837 & Fos transforming protein & 4 & 4.17 & UP & 83.59 & 0.001 & & & & & \\
\hline rno00480 & Glutathione metabolism & & & & & & 12 & 0.77 & D & 3.03 & 0.041 \\
\hline rno00340 & Histidine metabolism & & & & & & 9 & 0.58 & D & 4.73 & 0.019 \\
\hline SP_PIR & inflammatory response & 4 & 4.17 & UP & 16.51 & 0.027 & 13 & 1.26 & UP & 5.08 & 0.000 \\
\hline$S P \_P I R$ & Initiation factor & & & & & & 12 & 1.16 & $U P$ & 4.55 & 0.002 \\
\hline$S P \_P I R$ & Isomerase & & & & & & 17 & 1.65 & UP & 3.14 & 0.003 \\
\hline$S P \_P I R$ & lipid synthesis & & & & & & 19 & 1.84 & $U P$ & 3.82 & 0.000 \\
\hline rno00980 & Metabolism of xenobiotics by cyt. P450 & & & & & & 18 & 1.15 & $\mathrm{D}$ & 3.79 & 0.000 \\
\hline UP_SEQ & mutagenesis site & & & & & & 59 & 3.77 & $D$ & 1.75 & 0.042 \\
\hline rno04621 & NOD-like receptor signaling pathway & 5 & 5.21 & UP & 12.52 & 0.034 & & & & & \\
\hline$S P \_P I R$ & nucleotide-binding & & & & & & 99 & 9.58 & $U P$ & 1.36 & 0.024 \\
\hline SP_PIR & nucleus & 22 & 22.92 & UP & 2.01 & 0.026 & & & & & \\
\hline$S P \_P I R$ & phosphoprotein & & & & & & $\# \#$ & 27.49 & $U P$ & 1.24 & 0.000 \\
\hline IPR011993 & Pleckstrin homology-type & & & & & & 32 & 2.05 & $D$ & 2.27 & 0.027 \\
\hline
\end{tabular}


Table 2 DAVID Functional Annotation Charts, 2-h and 18-h Severe PE verses Vehicle (Continued)

\begin{tabular}{|c|c|c|c|c|c|c|c|c|c|c|c|}
\hline$S P \_P I R$ & protein biosynthesis & & & & & & 22 & 2.13 & $U P$ & 2.04 & 0.049 \\
\hline$S P \_P I R$ & protein transport & & & & & & 34 & 3.29 & $U P$ & 1.87 & 0.016 \\
\hline$S P \_P I R$ & Redox-active center & & & & & & 10 & 0.97 & UP & 4.74 & 0.005 \\
\hline SP_PIR & ribosome biogenesis & & & & & & 8 & 0.77 & UP & 5.31 & 0.014 \\
\hline$S P \_P I R$ & rna-binding & & & & & & 33 & 3.19 & $U P$ & 2.16 & 0.002 \\
\hline SM00360 & $R R M$ & & & & & & 21 & 2.03 & $U P$ & 2.69 & 0.015 \\
\hline SM00199 & SCY & 5 & 5.21 & UP & 18.26 & 0.003 & & & & & \\
\hline IPR001811 & Small chemokine, interleukin-8-like & 5 & 5.21 & UP & 25.22 & 0.002 & & & & & \\
\hline$S P \_P I R$ & Steroid biosynthesis & & & & & & 13 & 1.26 & UP & 5.08 & 0.000 \\
\hline rno00100 & Steroid biosynthesis & & & & & & 9 & 0.87 & $U P$ & 8.29 & 0.001 \\
\hline$S P \_P I R$ & sterol biosynthesis & & & & & & 11 & 1.06 & $U P$ & 7.31 & 0.000 \\
\hline$S P \_P I R$ & Transcription & 14 & 14.58 & $U P$ & 3.23 & 0.009 & & & & & \\
\hline$S P \_P I R$ & transcription regulation & 14 & 14.58 & $U P$ & 3.48 & 0.006 & & & & & \\
\hline$S P \_P I R$ & translocation & & & & & & 11 & 1.06 & $U P$ & 3.75 & 0.014 \\
\hline rno00350 & Tyrosine metabolism & & & & & & 10 & 0.64 & $D$ & 3.71 & 0.032 \\
\hline
\end{tabular}

Functional annotations significantly over-represented in the lists of up-regulated and down- regulated genes during 2-h and 18-h High-PE. Annotations unique to High-PE are highlighted in bold italics; annotations common to High-PE and Low-PE (Table 1) are in standard font. All other keys are the same as in Table 1. ${ }^{\mathrm{a}}$ No 2-h DOWN annotations meet $\mathrm{B} \& \mathrm{H}<0.05$

the 2-h Severe PE or 18-h Mild PE groups were confined to one or the other group. These data refute a similarity between early Severe PE and late Mild PE.

\section{Steroid synthesis during 18-h severe PE}

Three annotations were detected in the 18-h Severe PE gene lists which were associated with steroid and/or sterol biosynthesis. A total of 16 unique genes were contained within these annotations. These data are presented in Table 4. Most of these genes were contained on the KEGG pathway rno00100 (R. norvegicus Steroid Biosynthesis; http://www.kegg.jp/kegg-bin/show_pathway?rno00100).

This pathway terminates with several branches but all of the genes induced by Severe PE were located on the branch terminating with cholesterol.

HMGCR, HMGCS1 and IDI1 function upstream of rno00100 and were found on the KEGG pathway rno00900 (R. norvegicus Terpenoid Backbone Biosynthesis; http://www.kegg.jp/kegg-bin/show_pathway? rno00900). This pathway begins with acetyl-CoA, proceeds through 3-hydroxy-3-methyglutaryl-CoA (HMG$\mathrm{CoA})$, mevalonate, isopentenyl-diphosphate and farnesyldiphosphate, which is the metabolic intermediate that feeds KEGG Pathway rno00100.

\section{Discussion}

Microsphere-induced PE caused profound changes in gene expression in rat lungs even when RVSP was lower than typically considered clinically relevant. These data contrast sharply with previous results on the effects of this same PE model on transcriptional changes in hearts [23]. In this latter study, Zagorski et al. demonstrated an almost obligatory requirement for $\mathrm{PH}$ to cause altered gene expression in RV tissues [23]. In particular, 2-h Mild PE resulted in no statistically significant transcriptional changes in RVs and few changes after 18-h. The effect of Mild PE on gene expression in lung tissue reported here was much more dramatic. 2-h of Mild PE with minimal $\mathrm{PH}$ was sufficient to cause numerous changes in gene expression and statistically significant alteration in at least 21 expression pathways or other gene group annotations. Examination of the annotations enriched in the 2-h Mild PE "UP" gene expression data revealed several pro-inflammatory annotation terms. The abundance of pro-inflammatory annotations enriched in 2-h Mild PE samples indicates that lungs exposed to even mild $\mathrm{PE}$ with minimal $\mathrm{PH}$ rapidly enter into a pro-inflammatory state. This data supports a conclusion that even mild PE has the potential to initiate damage to lung tissues. This is in stark contrast to the total lack of right ventricular inflammation seen in the microsphere model of Mild PE [19-25].

Mild and Severe PE are hemodynamically distinct at 2-h post-PE, with only the latter having $\mathrm{PH}$. This brings into question the stimuli imparted on lungs with 2-h Mild PE which are responsible for the large changes in gene expression. The most likely explanation is ischemia, which is often considered synonymous with hypoxia. However, ischemia resulting from occlusion of the pulmonary vasculature is unique, since the pulmonary artery circulates oxygen-poor and nutrient-depleted blood derived from the venous circulation. In essence, even normal circulation through the pulmonary artery is hypoxic, and occluded flow through the pulmonary artery 
Table 3 DAVID Functional Annotation Charts, 2-h Severe PE and 18-h Mild PE verses Vehicle

\begin{tabular}{|c|c|c|c|c|c|c|c|c|c|c|c|}
\hline \multirow[b]{2}{*}{ Category } & \multirow[b]{2}{*}{ Term } & \multicolumn{5}{|c|}{ a'-h Severe-PE verses Vehicle } & \multicolumn{5}{|c|}{ 18-h Mild-PE verses Vehicle } \\
\hline & & $\mathrm{Ct}$ & $\%$ & Dir & Fold & $\mathrm{B} \& \mathrm{H}$ & $\mathrm{Ct}$ & $\%$ & Dir & Fold & $\mathrm{B} \& \mathrm{H}$ \\
\hline SP_PIR & acetylation & & & & & & 78 & 14.03 & UP & 1.51 & 0.009 \\
\hline SP_PIR & activator & 7 & 7.29 & UP & 5.58 & 0.025 & & & & & \\
\hline rno00970 & Aminoacyl-tRNA biosynthesis & & & & & & 8 & 1.44 & UP & 5.56 & 0.017 \\
\hline rno00330 & Arginine and proline metabolism & & & & & & 9 & 1.62 & UP & 4.72 & 0.015 \\
\hline rno05217 & Basal cell carcinoma & & & & & & 10 & 1.11 & $\mathrm{D}$ & 4.28 & 0.016 \\
\hline IPR011700 & Basic leucine zipper & 4 & 4.17 & UP & 41.80 & 0.004 & & & & & \\
\hline IPR004827 & Basic-leucine zipper (bZIP) transcription factor & 8 & 8.33 & UP & 28.54 & 0.000 & & & & & \\
\hline SM00338 & BRLZ & 8 & 8.33 & UP & 20.66 & 0.000 & & & & & \\
\hline IPR011616 & bZIP transcription factor, bZIP-1 & 4 & 4.17 & UP & 25.44 & 0.015 & & & & & \\
\hline rno04062 & Chemokine signaling pathway & & & & & & 20 & 3.60 & UP & 3.25 & 0.001 \\
\hline$S P \_P I R$ & chemotaxis & 4 & 4.17 & UP & 20.78 & 0.025 & 11 & 1.98 & $U P$ & 10.30 & 0.000 \\
\hline rno04610 & Complement and coagulation cascades & & & & & & 10 & 1.80 & UP & 3.97 & 0.019 \\
\hline$S P \_P I R$ & cytokine & 9 & 9.38 & UP & 15.21 & 0.000 & 16 & 2.88 & $U P$ & 4.88 & 0.000 \\
\hline rno04060 & Cytokine-cytokine receptor interaction & & & & & & 23 & 4.14 & UP & 3.25 & 0.000 \\
\hline SP_PIR & disulfide bond & & & & & & 76 & 13.67 & UP & 1.43 & 0.044 \\
\hline SP_PIR & DNA binding & 6 & 6.25 & UP & 7.38 & 0.028 & & & & & \\
\hline SP_PIR & dna-binding & 15 & 15.63 & UP & 3.75 & 0.002 & & & & & \\
\hline UP_SEQ & DNA-binding region: Basic motif & 10 & 10.42 & UP & 15.44 & 0.000 & & & & & \\
\hline UP_SEQ & domain: Leucine-zipper & 9 & 9.38 & UP & 19.96 & 0.000 & & & & & \\
\hline rno00982 & Drug metabolism & & & & & & 13 & 1.45 & $\mathrm{D}$ & 3.94 & 0.004 \\
\hline rno04512 & ECM-receptor interaction & & & & & & 14 & 1.56 & D & 3.77 & 0.005 \\
\hline PIRSF001719 & fos transforming protein & 4 & 4.17 & UP & 109.20 & 0.000 & & & & & \\
\hline IPR000837 & Fos transforming protein & 4 & 4.17 & UP & 83.59 & 0.001 & & & & & \\
\hline rno00480 & Glutathione metabolism & & & & & & 9 & 1.00 & $\mathrm{D}$ & 3.93 & 0.042 \\
\hline rno00340 & Histidine metabolism & & & & & & 7 & 0.78 & D & 6.37 & 0.017 \\
\hline$S P \_P I R$ & inflammatory response & 4 & 4.17 & UP & 16.51 & 0.027 & 11 & 1.98 & $U P$ & 8.18 & 0.000 \\
\hline rno00980 & Metabolism of xenobiotics by cytochrome P450 & & & & & & 13 & 1.45 & $\mathrm{D}$ & 4.73 & 0.002 \\
\hline rno04621 & NOD-like receptor signaling pathway & 5 & 5.21 & UP & 12.52 & 0.034 & 10 & 1.80 & $U P$ & 4.49 & 0.016 \\
\hline SP_PIR & nucleus & 22 & 22.92 & UP & 2.01 & 0.026 & & & & & \\
\hline SP_PIR & oxidoreductase & & & & & & 42 & 4.68 & $\mathrm{D}$ & 1.89 & 0.034 \\
\hline rno05020 & Prion diseases & & & & & & 7 & 1.26 & UP & 5.56 & 0.028 \\
\hline SP_PIR & ribosome biogenesis & & & & & & 7 & 1.26 & UP & 8.85 & 0.007 \\
\hline SM00199 & $S C Y$ & 5 & 5.21 & $U P$ & 18.26 & 0.003 & 10 & 1.80 & $U P$ & 8.76 & 0.000 \\
\hline IPR001811 & Small chemokine, interleukin-8-like & 5 & 5.21 & UP & 25.22 & 0.002 & 10 & 1.80 & $U P$ & 8.70 & 0.001 \\
\hline SP_PIR & Transcription & 14 & 14.58 & UP & 3.23 & 0.009 & & & & & \\
\hline SP_PIR & transcription regulation & 14 & 14.58 & UP & 3.48 & 0.006 & & & & & \\
\hline
\end{tabular}

Functional annotations significantly over-represented in the lists of up-regulated and down-regulated genes during 2-h Severe PE and 18-h Mild PE. Annotations unique to both treatments are highlighted in bold Italics; unique annotations are in standard font. Keys are the same as in Table 1. ${ }^{\text {a No }} 2$-h DOWN Annotations meet $\mathrm{B} \& \mathrm{H}<0.05$

has no effect on oxygenation of lung tissue, which is dependent on the separate bronchial circulation. Furthermore, lung tissue is continuously exposed to atmospheric oxygen via the airways. It seems unlikely that hypoxia accounts for the early lung transcriptional response to Mild PE. Supporting evidence for this conclusion is contained in this study. Expression of the hypoxia marker genes Hif1 (hypoxia-inducible factor-1) and Hyou1 (hypoxia up-regulated 1) were up-regulated in the 18-h Severe PE treatment group by modest 1.6851- 
Table 4 Steroid/Sterol Biosynthesis Genes

\begin{tabular}{llll}
\hline Symbol & Fold & Dir. & Gene Name \\
\hline CH25H & 6.84 & UP & Cholesterol 25-hydroxylase \\
DHCR24 & 2.33 & UP & 24-dehydrocholesterol reductase \\
DHCR7 & 2.15 & UP & 7-dehydrocholesterol reductase \\
FDFT1 & UP & Farnesyl diphosphate farnesyl transferase 1 \\
FDPS & $1.56^{a}$ & UP & Farnesyl diphosphate synthase (farnesyl pyrophosphate synthetase, \\
HMGCR & 1.89 & UP & dimethylallyltranstransferase, geranyltranstransferase) \\
HMGCS1 & $2.11^{\text {a }}$ & UP & 3-hydroxy-3-methylglutaryl-Coenzyme A reductase \\
HSD17B12 & 3.74 & UP & 3-hydroxy-3-methylglutaryl-Coenzyme A synthase 1 (soluble) \\
HSD17B7 & UP & Hydroxysteroid (17-beta) dehydrogenase 12 \\
IDI1 & 3.03 & UP & Hydroxysteroid (17-beta) dehydrogenase 7 \\
MVD & 4.33 & UP & Isopentenyl-diphosphate delta isomerase 1 \\
NSDHL & 8.61 & UP & Mevalonate (diphospho) decarboxylase \\
SC4MOL & 3.34 & UP & NAD(P) dependent steroid dehydrogenase-like \\
SC5DL & 1.84 & UP & Sterol-C4-methyl oxidase-like \\
SOAT1 & 1.9 & UP & Sterol-C5-desaturase (ERG3 delta-5-desaturase homolog, S. cerevisiae) \\
SQLE & $2.33^{a}$ & UP & Sterol O-acyltransferase 1
\end{tabular}

Steroid and sterol biosynthesis genes altered in the 18-h Severe PE treatment group. The three steroid/sterol annotations from Table 2 contained a total of 16 unique genes. All of the original DAVID downloads of PE-regulated annotations shown in Tables 1 and 2 and included lists of the genes within an annotation that were also altered by PE. These gene lists were very large and were not included in Tables 1, 2 and 3 to save space. The three annotations "SP_PIR Steroid biosynthesis", "rno00100 Steroid biosynthesis" and "SP_PIR Sterol biosynthesis" contained 13, 9 and 11 genes, respectively. The 16 genes shown above represent the total unique genes. "Dir", direction of fold-change. ${ }^{a}$ Average fold-change of 2 or more probesets for a single gene

fold and 3.3772-fold levels, respectively (Additional file 2E; lines 6823 and 4267) but neither was up-regulated by the Mild PE treatment. These results discount a role for lung hypoxia following PE, at least at the Mild PE dose of microspheres.

It seems reasonable that some hemostatic disruption related to ischemia, but not based on transfer of oxygen and/ or nutrients to lung tissue, was responsible for the effects on gene expression seen in this study. An intriguing possibility is "stop-of-flow", a phenomenon introduced by Fisher and co-workers [29-34]. Vascular endothelium are adapted to conditions of flow in vivo, with cell membranes and cytoskeletons aligning along the axis of blood flow. This can also be mimicked in vitro by applying flow over cells which were initially cultured in the absence of flow [33]. Endothelial cells grown in the absence of flow show a random organization of membranes and cytoskeletal structures, but when a laminar flow is applied to these cultures the cells adopt a flow-axial organization similar to that seen in vivo. Importantly, when flow is discontinued on cultures of flow-adapted cells, several signaling pathways are activated, including a signaling cascade mediated by NADPH oxidase 2-dependent ROS production (reactive oxygen species; 32 ). This also occurs in vivo in isolated perfused lungs subjected to ischemia. Pulmonary endothelial membrane depolarization, $\mathrm{H} 2 \mathrm{O} 2$ production and increased intracellular Ca2+ have been observed within 10-15 s after the onset of non-hypoxic ischemia [34]. This rapid response can easily accommodate the increased gene expression seen in rats with 2-h Mild PE. Several comprehensive reviews have been published on the proposed general applicability of the "stop-of-flow" mechanism to explain the pathophysiology of tissue ischemia, including the ischemia associated with PE [35-37].

Finally, 18-h Severe PE resulted in the over-expression of genes present in several gene annotations related to steroid, lipid, and/or cholesterol biosynthesis. These results are consistent with a recent report that bile acids accumulate in lung tissues suffering from pulmonary artery hypertension; bile acids are downstream of cholesterol biosynthesis [38]. They are also consistent with numerous studies that have demonstrated the efficacy HMG-CoA reductase inhibitors (statins) in reducing the severity of pulmonary hypertension in both chronic hypoxia and monocrotaline animal models [39-44], although contradictory results have also been observed [45]. Several mechanisms, un-linked to the known effect of statin drugs on reducing serum cholesterol, have been proposed to explain the efficacy of statins for $\mathrm{PH}$ but a clear explanation is premature.

Clinical relevance includes the potential hypothesis that PE without PH may produce inflammatory changes in the lung, leading to lung-initiated, systemic inflammation, and increased risk of ongoing hypercoagulability and clot recurrence $[13,14]$. Humans with PE have 4-7 fold increases in circulating biomarkers of inflammation 
(tumor necrosis factor, $\mathrm{C}$ reactive protein, interleukin 6 and myeloperoxidase) that return to near normal levels after three months of treatment [46, 47]. Approximately $1 / 3$ of patients with PE have sustained unresolved perfusion defects after PE diagnosis [48]. A growing body of literature has found that treatment with statins reduce circulating concentrations of IL-6, CRP and monocyte chemoattractant protein 1 , and may reduce VTE recurrence [49]. Our data suggest persistent pulmonary vascular occlusion, even with minimal or absent $\mathrm{PH}$ may cause lung inflammation with PE. These data may imply that early re-canalization should decrease this inflammatory response. This is a prime goal of "Pulmonary Embolism Response Teams" being organized at many sites around the US with the goal of rapid recanalization of pulmonary arteries in patients with severe PE [50].

\section{Conclusion}

This is the first report to show that mild pulmonary embolism produces profound alteration in gene transcription in lungs, primarily in terms of increased expression of genes encoding inflammatory chemokines and cytokines and cholesterol synthesis. These data show that unresolved pulmonary vascular occlusion produces ongoing lung inflammation even in the absence of elevated pulmonary arterial pressures. Translational implications include the adverse effects of ongoing inflammation from unresolved pulmonary vascular occlusions, and conversely, possible benefit of treating PE to an endpoint of complete clot resolution.

\section{Additional files}

Additional file 1: Rat lung 6-group 2-way ANOVA. (XLS 3757 kb)

Additional file 2: Pairwise t-test of PE treatments. (XLS $2775 \mathrm{~kb}$ )

Additional file 3: ANOVAs of 2-hour and 18-hour PE treatments. (XLS $1660 \mathrm{~kb}$ )

\section{Acknowledgements}

This work was conducted while the authors were in residence at Carolinas Medical Center, Charlotte NC. We would like to thank the members of the Charlotte Mecklenburg Genomics Consortium Microarray Core Facility for performing the GeneChip hybridizations: Judy Vachris, Kris Bennett and Dr. Nury Steuerwald, Facility Director. We also thank Drs. Helen Gruber and Emilio Marrero of the Orthopedic Surgery Research Laboratory, Carolinas Medical Center, for assistance with GeneSifter.

\section{Funding}

This project was supported in part and by grants from the Education and Research Committee of the Charlotte-Mecklenburg Health Services Foundation to John Zagorski (grants 204114 and 204159) and the Lilly Foundation Physician Scientist Initiative Award to Jeffrey Kline.

\section{Availability of data and materials}

All microarray data have been deposited in the NIH/NCBI "GEO" database (http://www.ncbi.nlm.nih.gov/projects/geo; GEO accession number GSE13535).

\section{Authors' contributions}

JZ conceived the study, carried out the molecular and Affymetrix studies, data analysis and drafted the manuscript. JK participated in the conception and design of the study, developed and supervised the animal model, participated in drafting and editing the manuscript. Both authors read and approved the final manuscript.

\section{Competing interests}

The authors declare that they have no competing interests.

\section{Ethics approval and consent to participate}

All experiments were conducted in accordance with the $\mathrm{NIH}$ Guide For the Care and Use of Laboratory Animals and were approved by the Institutional Animal Care and Use Committee (IACUC) of Carolinas Medical Center,

Charlotte NC (Protocols 4-02-01A and 11-00-01A).

\section{Author details}

'Department of Math and Sciences, Gaston College, Dallas, NC 28014, USA. ${ }^{2}$ Department of Emergency Medicine and Department of Cellular and Integrative Physiology, Indiana University Medical School, 720 Eskanazi Avenue, Indianapolis, IN 46202, USA.

Received: 2 April 2016 Accepted: 10 July 2016

Published online: 19 July 2016

\section{References}

1. Kline JA, Kabrhel C. Emergency evaluation for pulmonary embolism, Part 1: clinical factors that increase risk. J Emerg Med. 2015;48:771-80.

2. Kline JA, Kabrhel C. Emergency evaluation for pulmonary embolism, Part 2: diagnostic approach. J Emerg Med. 2015;49:104-17.

3. Goldhaber SZ, Elliott CG. Acute pulmonary embolism: part l: epidemiology, pathophysiology, and diagnosis. Circulation. 2003;108:2726-9.

4. Goldhaber SZ, Elliott CG. Acute pulmonary embolism: part II: risk stratification, treatment, and prevention. Circulation. 2003;108:2834-8.

5. White $\mathrm{RH}$. The epidemiology of venous thromboembolism. Circulation. 2003:107:14-8.

6. Watts JA, Marchick MR, Kline JA. Right ventricular heart failure from pulmonary embolism: key distinctions from chronic pulmonary hypertension. J Card Fail. 2010;16:250-9.

7. Morris TA. Why acute pulmonary embolism becomes chronic thromboembolic pulmonary hypertension: clinical and genetic insights. Curr Opin Pulm Med. 2013;19:422-9.

8. Lang IM, Pesavento R, Bonderman D, Yuan JX. Risk factors and basic mechanisms of chronic thromboembolic pulmonary hypertension: a current understanding. Eur Respir J. 2013:41:462-8.

9. Yaoita N, Shirakawa R, Fukumoto Y, et al. Platelets are highly activated in patients of chronic thromboembolic pulmonary hypertension. Arterioscler Thromb Vasc Biol. 2014;34:2486-94.

10. Quarck R, Wynants M, Verbeken E, Meyns B, Delcroix M. Contribution of inflammation and impaired angiogenesis to the pathobiology of chronic thromboembolic pulmonary hypertension. Eur Respir J. 2015:46:431-43.

11. Yi ES, Kim H, Ahn H, et al. Distribution of obstructive intimal lesions and their cellular phenotypes in chronic pulmonary hypertension. A morphometric and immunohistochemical study. Am J Respir Crit Care Med. 2000;162:1577-86

12. Chow V, Reddel C, Pennings G, et al. Persistent global hypercoagulability in long-term survivors of acute pulmonary embolism. Blood Coagul Fibrinolysis. 2015;26:537-44.

13. Mearns ES, Coleman Cl, Patel D, et al. Index clinical manifestation of venous thromboembolism predicts early recurrence type and frequency: a metaanalysis of randomized controlled trials. J Thromb Haemost. 2015;13:1043-52.

14. Hoeper MM, Mayer E, Simonneau G, et al. Chronic thromboembolic pulmonary hypertension. Circulation. 2006;113:2011-20.

15. Savchenko AS, Martinod K, Seidman MA, et al. Neutrophil extracellular traps form predominantly during the organizing stage of human venous thromboembolism development. J Thromb Haemost. 2014;12:860-70.

16. Eagleton MJ, Henke PK, Luke CE, et al. Inflammation and intimal hyperplasia associated with experimental pulmonary embolism. J Vasc Surg. 2002;36:581-8.

17. Diehl $\mathrm{P}$, Aleker M, Helbing T, et al. Increased platelet, leukocyte and endothelial microparticles predict enhanced coagulation and vascular inflammation in pulmonary hypertension. J Thromb Thrombolysis. 2011;31:173-9.

18. Zagorski J, Debelak J, Gellar M, Watts JA, Kline JA. Chemokines accumulate in the lungs of rats with severe pulmonary embolism induced by polystyrene microspheres. J Immunol. 2003;171:5529-36. 
19. Jones AE, Watts JA, Debelak JP, Thornton LR, Younger JD, Kline JA. Inhibition of prostaglandin synthesis during polystyrene microsphereinduced pulmonary embolism in the rat. Am J Physiol Lung Cell Mol Physiol. 2003;284:L1072-81.

20. Watts JA, Zagorski J, Gellar MA, Stevinson BG, Kline JA. Cardiac inflammation contributes to right ventricular dysfunction following experimental pulmonary embolism in rats. J Mol Cell Cardiol. 2006;41:296-307.

21. Zagorski J, Gellar MA, Obraztsova M, Kline JA, Watts JA. Inhibition of CINC-1 decreases right ventricular damage caused by experimental pulmonary embolism in rats. J Immunol. 2007:179:7820-6.

22. Watts JA, Gellar MA, Obraztsova M, Kline JA, Zagorski J. Role of inflammation in right ventricular damage and repair following experimental pulmonary embolism in rats. Int J Exp Pathol. 2008;89:389-99.

23. Zagorski J, Sanapareddy N, Gellar MA, Kline JA, Watts JA. Transcriptional profile of right ventricular tissue during pulmonary embolism in rats. Physiol Genomics. 2008;34:101-11.

24. Zagorski J, Obraztsova M, Gellar MA, Kline JA, Watts JA. Transcriptional changes in right ventricular tissues are enriched in the outflow tract compared with the apex during chronic pulmonary embolism in rats. Physiol Genomics. 2009;39:61-71.

25. Watts JA, Gellar MA, Stuart LK, Obraztsova M, Kline JA. Pro-inflammatory events in right ventricular damage during pulmonary embolism: effects of treatment with ketorolac in rats. J Cardiovasc Pharmaocol. 2009;54:246-52.

26. Chomczynski P, Sacchi N. Single-step method of RNA isolation by acid guanidinium thiocyanate-phenol-chloroform extraction. Anal Biochem. 1987;162:156-9.

27. Dennis Jr G, Sherman BT, Hosack DA, Yang J, Gao W, Lane HC, et al. DAVID: Database for Annotation, Visualization, and Integrated Discovery. Genome Biol. 2003;4:P3.

28. Huang DW, Sherman BT, Lempicki RA. Systematic and integrative analysis of large gene lists using DAVID Bioinformatics Resources. Nature Protoc. 2009:4:44-57.

29. Fisher AB, Dodia C, Tan Z, Eckenhoff RG. Oxygen-dependent lipid peroxidation during lung ischemia. J Clin Invest. 1991;88:674-9.

30. Atochina EN, Muzykantov VR, Al-Mehdi AB, Danilov SM, Fisher AB. Normoxic lung ischemia/reperfusion accelerates shedding of angiotensin converting enzyme from the pulmonary endothelium. Am J Respir Crit Care Med. 1997;56:1114-9.

31. Zhao G, Al-Mehdi AB, Fisher AB. Anoxia-reoxygenation verses ischemia in isolated rat lungs. Am J Physiol Lung Cell Mol Physiol. 1997;17:L1112-7.

32. Al-Mehdi AB, Zhao G, Dodia C, Tozawa K, Costa K, Muzykantov V, et al. Endothelial NADPH oxidase as the source of oxidants in lungs exposed to ischemia or high $\mathrm{K}^{+}$. Circ Res. 1998;83:730-7.

33. Wei Z, Costa K, Al-Mehdi AB, Dodia C, Muzykantov V, Fisher AB. Simulated ischemia in flow-adapted endothelial cells leads to generation of reactive oxygen species and cell signaling. Circ Res. 1999;85:682-9.

34. Song C, Al-Mehdi AB, Fisher AB. An immediate endothelial cell signaling response to lung ischemia. Am J Physiol Lung Cell Mol Physiol. 2001;281:L993-L1000.

35. Chatterjee S, Chapman KE, Fisher AB. Lung ischemia: a model for endothelial mechanotransduction. Cell Biochem Biophys. 2008;52(3):125-38.

36. Browning EA, Chatterjee S, Fisher AB. Stop the flow: a paradigm for cell signaling mediated by reactive oxygen species in the pulmonary endothelium. Annu Rev Physiol. 2012;74:403-24.

37. Chatterjee S, Nieman GF, Christie JD, Fisher AB. Sheer stress-induced mechanotransduction with lung ischemia: lessons from basic research can inform lung transplantation. Am J Physiol Lung Cell Mol Physiol. 2014;307(9):L668-80.

38. Zhao YD, Yun HZH, Peng J, Yin L, Chu L, Wu L, et al. De novo synthesize of bile acids in pulmonary arterial hypertension lung. Metabolomics. 2014;10:1169-75.

39. Nishumura T, Vaszar LT, Faul JL, Zhao G, Berry GJ, Shi L, et al. Simvastatin rescues rats from fatal pulmonary hypertension by inducing apoptosis of neointimal smooth muscle cells. Circulation. 2003;108:1640-5.

40. Taraseviciene-Stewart L, Scerbavicius R, Choe K-H, Cool C, Wood K, Tuder R, et al. Simvastatin causes endothelial cell apoptosis and attenuates severe pulmonary hypertension. Am J Physiol Lung Cell Mol Physiol. 2006;291:L668-76.

41. Girgis RE, Mozammel S, Champion HC, Li D, Peng X, Shimoda L, et al. Regression of chronic hypoxic pulmonary hypertension by simvastatin. Am J Physiol Lung Cell Mol Physiol. 2007;292:L1105-10.

42. Satoh M, Satoh A. 3-hydroxy-3-methylglutaryl-CoA reductase inhibitors and phosphodiesterase type $\mathrm{V}$ inhibitors attenuate right ventricular pressure and remodeling in a rat model of pulmonary hypertension. $J$ Pharmaceut Sci. 2008;11:118s-30s.

43. Hsu H-H, Ko W-J, Hsu J-Y, Chen J-S, Lee Y-C, Lai I-R, et al. Simvastatin ameliorates established pulmonary hypertension through a heme oxygenase-1 dependent pathway in rats. Respir Res. 2009;10:32.

44. Lee Y, Kim KC, Cho M-S, Hong YM. Changes of pulmonary pathology and gene expressions after simvastatin treatment in the monocrotaline-induced pulmonary hypertension rat model. Korean Circ J. 2011;41:518-27.

45. McMurray MS, Bonnet S, Michelakis ED, Bonnet S, Haromy A, Archer SL. Statin therapy, alone or with rapamycin, does not reverse monocrotaline pulmonary arterial hypertension: the rapamycin-atorvastatin-simvastatin study. Am J Physiol Lung Cell Mol Physiol. 2007;293:L933-40.

46. Halici B, Sarinc US, Gunay E, et al. Assessment of inflammatory biomarkers and oxidative stress in pulmonary thromboembolism: follow-up results. Inflammation. 2014:37:1186-90.

47. Stewart LK, Nordenholz KE, Courtney DM, et al. Comparison of biomarkers in patients with acute submassive pulmonary embolism treated with fibrinolysis versus placebo at three-month follow-up. unknown. In press.

48. van EJ, Douma RA, Kamphuisen PW, et al. Clot resolution after 3 weeks of anticoagulant treatment for pulmonary embolism: comparison of computed tomography and perfusion scintigraphy. J Thromb Haemost. 2013;11:679-85.

49. Rodriguez AL, Wojcik BM, Wrobleski SK, Myers Jr DD, Wakefield TW, Diaz JA. Statins, inflammation and deep vein thrombosis: a systematic review. J Thromb Thrombolysis. 2012;33:371-82.

50. Provias T, Dudzinski DM, Jaff MR, et al. The Massachusetts General Hospital Pulmonary Embolism Response Team (MGH PERT): creation of a multidisciplinary program to improve care of patients with massive and submassive pulmonary embolism. Hosp Pract. 2014;42:31-7.

\section{Submit your next manuscript to BioMed Central and we will help you at every step:}

- We accept pre-submission inquiries

- Our selector tool helps you to find the most relevant journal

- We provide round the clock customer support

- Convenient online submission

- Thorough peer review

- Inclusion in PubMed and all major indexing services

- Maximum visibility for your research

Submit your manuscript at www.biomedcentral.com/submit

) Biomed Central 